\title{
A review of continuous vs intermittent androgen deprivation therapy: Redefining the gold standard in the treatment of advanced prostate cancer. Myths, facts and new data on a "perpetual dispute"
}

Zisis Kratiras, Charalampos Konstantinidis, Konstantinos Skriapas

Department of Urology, “Koutlibanio" General Hospital of Larisa (ZK, KS), Larissa, and Department of Urology and Neuro-urology, National Rehabilitation Center (CK), Athens, Greece

\section{ABSTRACT}

Objectives: To review the literature and present new data of continuous androgen deprivation therapy (ADT) vs intermittent androgen deprivation (IAD) as therapies for prostate cancer in terms of survival and quality of life and clarify practical issues in the use of IAD.

Materials and Methods: We conducted a systematic search on Medline and Embase databases using "prostatic neoplasm" and "intermittent androgen deprivation" as search terms. We reviewed meta-analyses, randomised controlled trials, reviews, clinical trials and practise guidelines written in English from 2000 and onwards until 01/04/2013. Ten randomized controlled trials were identified. Seven of them published extensive data and results randomizing 4675 patients to IAD versus CAD. Data from the other three randomized trials were limited.

Results: Over the last years studies confirmed that IAD is an effective alternative approach to hormonal deprivation providing simultaneously several potential benefits in terms of quality of life and cost effectiveness. Thus, in patients with non metastatic, advanced prostate cancer IAD could be used as standard treatment, while in metastatic prostate cancer IAD role still remains ambiguous.

Conclusions: Nowadays, revaluation of the gold standard of ADT in advanced prostate cancer appears essential. Recent data established that IAD should no longer be considered as investigational, since its effectiveness has been proven, especially in patients suffering from non-metastatic advanced prostate cancer.

\section{ARTICLE INFO}

Key words:

Prostatic Neoplasms;

Therapeutics; Quality of Life;

Androgens

Int Braz J Urol. 2014; 40: 3-15

Submitted for publication:

June 11, 2013

Accepted after revision:

October 02, 2013

\section{INTRODUCTION}

\section{Rationale}

Prostate cancer continues to be the leading malignancy afflicting males in the Western world and the second leading cause of cancer death after lung cancer $(1,2)$. Androgen deprivation therapy (ADT) is the mainstay of therapy for men with advanced prostate cancer. According to European Association of Urology (EAU) guidelines, GnRH analogues have become the standard of care in ADT (3). They offer a non surgical castration, having lower risk of cardiotoxicity compared to DES $(4,5)$ and having the potential for reversi- 
bility enabling the use of intermittent androgen deprivation (IAD).

Continuous $\mathrm{AD}$ (CAD) is based on the assumption that malignant prostate cells require androgen stimulation for growth and proliferation. Deprivation of the androgens will impede the growth of malignant prostate cells. Testosterone is the primary circulating androgen representing more than 90\% of androgenic activity. Testosterone's production is controlled by a regulatory feedback between the hypothalamus-pituitary axis and the testes. GnRH is secreted in pulses from the hypothalamus and stimulates the release of luteinizing hormone (LH) from the pituitary gland. LH subsequently stimulates secretion of testosterone predominantly by the testes by binding to receptors. Testosterone (T) exerts a negative feedback on GnRH through androgen receptors in the hypothalamus and the pituitary gland. In prostate cell testosterone is converted into 5-a-dihydrotestosterone (DHT) via an enzyme called 5-a reductase. $\mathrm{GnRH}$ analogues provoke an initial surge in LH, $\mathrm{T}$ and DHT also known as flare phenomenon but overtime these hormones are suppressed through the negative feedback on hypothalamus.

Despite its undeniable effectiveness as a treatment, ADT is associated with multiple side effects including loss of libido, hot flushes, erectile dysfunction, cognitive dysfunction, decreased energy, osteoporosis, increased fracture risk, fatigue, a metabolic syndrome characterized by abdominal obesity and insulin resistance, gynecomastia, anemia and depression (6). The recognition and the evaluation of these side effects aroused the need for less patient exposure to ADT.

In 1986, in the pre prostate-specific antigen (PSA) era, Klotz et al. were the first to report the clinical use of IAD for advanced prostate cancer in 20 patients with symptomatic metastatic disease treated with DES. They withdrew DES once the patients demonstrated a good clinical response and treatment was reinitiated when patients became symptomatic again. That led to reduction of side effects, improved the quality of life of patients and demonstrated that treatment could be discontinued (7). The theoretical background of IAD was developed and proposed by Bruchovsky et al. In their preclinical studies they found that the re-exposure of prostate cancer cell to androgen could restore and increase the apoptotic potential of the androgen dependant cell that survived the $\mathrm{AD}(8,9)$. Using the Shionongi IAD tumor mouse model, they reported a prolongation of time to castration resistance up to three times with intermittent therapy compared with the continuous treatment models (10-12). Hence, apart from reducing side effects and ameliorating quality of life $(\mathrm{QoL}), \mathrm{IAD}$ appears to be very appealing in the current era of cost-effective medicine, as it represents significant savings. Therefore IAD seems promising in many fronts: better QoL with reduced side effects, decreased treatment expenses and possible delayed onset of castration-resistant disease.

\section{Indications}

Several Phase II $(13,14)$ and randomized Phase III (15-24) trials have been conducted to investigate $I A D$ as an alternative treatment for advanced or metastatic prostate cancer, providing data that IAD is a treatment option in such patients. In 2012 EAU stated in its guidelines that "IAD is currently widely offered to patients with $\mathrm{PCa}$ in various clinical settings, and its status should no longer be regarded as investigational (LE: 2)" (25).

\section{MATERIALS AND METHODS}

\section{Search Strategy}

We performed a wide systematic literature research in the Medline and Embase databases. Prostate neoplasm and intermittent androgen deprivation were the search terms we used for specific study designs: meta-analysis, randomised controlled trials, reviews, clinical trials and practise guidelines. Our research was limited to studies published in English language from 2000 and onwards until 01/04/2013. Reference lists of the included articles were secondly hand-searched for studies that were not identified by the database search.

\section{Study Selection Criteria}

- Types of participants: the selected trials enrolled patients suffering from advanced (biochemical recurrence after definite therapy) or metastatic prostate cancer. 
- Type of studies: we included randomized controlled trials comparing the use of intermittent to continuous androgen deprivation as therapy in advanced prostate cancer.

- Type of outcome measures: primary outcomes; overall survival, cancer-specific survival, time to progression and secondary outcomes; adverse effects, quality of life.

Assessment of selected studies and data collection process

Title and abstract from all the retrieved studies were evaluated. For every study that fulfilled the inclusion criteria, the complete article were retrieved, assessed and included or excluded according to the pre-mentioned criteria. Data were either collected directly from the text or calculated from the published information. A total of 121 references were identified and assessed. From them, 44 were selected and full-article was retrieved for evaluation. Seven randomized multicenter phase III trials were identified and included (18-24) in the review. These seven studies enrolled and randomized 4675 patients to continuous versus intermittent androgen deprivation therapy, publishing extensive data and results. Hence, another 3 randomized trials (1517) were retrieved from the reference list of the retrieved articles but they lack of sufficient published data.

\section{RESULTS}

\section{Phase II studies}

In the early 1990's, the availability of reversible agents made it possible to utilize IAD, switching from treatment to non treatment periods. Furthermore, serum PSA allowed a more accurate monitoring of the disease's progression than clinical condition. As a result, PSA thresholds were used as trigger points for withdrawing and reinitiating therapy. In 1995 Goldenberg et al. were the first to define the trigger points for IAD using serum PSA measurements. In their study, therapy was withdrawn when serum PSA had reached a nadir below 4 $\mathrm{ng} / \mathrm{mL}$ and reintroduced when serum PSA increased to value between $10 \mathrm{ng} / \mathrm{mL}$ and $20 \mathrm{ng} / \mathrm{mL}$ (13).

Several clinical Phase II trials have been published since then. These trials were single-institution with heterogeneous population of patients and with different stages of the disease. In 2007, Shaw et al. published a meta-analysis including 1446 patients participating in 10 phase II trials. This meta-analysis estimated the 5 year overall survival to be $90 \%$ in patients with localized disease, $86 \%$ in patients with biochemical recurrence and $68 \%$ in patients with metastatic disease. Three factors were identified as independently prognostic factors through these trials: the initial PSA, the PSA nadir after AD and the duration of the off-treatment period (14). Thus, anti-androgen monotherapy proved to be inferior as a treatment in metastatic disease. In this meta-analysis, the percentage of the off-treatment period was 39\% while a low PSA nadir after AD appeared to be a good predictor of the overall survival, of the disease free survival and of the off-treatment period (14). In a recent systematic review, Abrahamsson concluded that IAD is at least as effective as combined androgen deprivation and has improved tolerability over CAD (26). Phase II trials concluded that IAD shows good acceptance and feasibility and that QoL is consistently improved during off-treatment periods, although most of the studies have not used validated QoL instruments. Nevertheless, the main question yet to be answered is the effect of IAD on overall survival. This question along with others such as the QoL output, which patients will benefit most and whether PSA can be used as a surrogate biomarker could only be answered in Phase III clinical trials.

\section{Phase III studies}

\section{Mixed populations}

Several randomized phase III trials have been conducted and their results have been reported or published. Studies reporting survival data concluded that there is no statistically important difference between the two groups in overall and cancer-specific survival $(15,16)$. The majority of these trials were underpowered, enrolling a relatively small population of patients. 
In the FinnProstate VII trial (19), 554 patients with locally advanced or metastatic cancer were enrolled in the study. The induction period of treatment was 6 months. Patients in whom PSA nadir value after the induction therapy was less than $10 \mathrm{ng} / \mathrm{mL}$, or by $50 \%$ or more reduced from the initial pre-treatment value, were randomized in two groups, one treated with continuous $\mathrm{AD}$ and the other with intermittent $\mathrm{AD}$. In the IAD arm the PSA level to stop treatment was below $10 \mathrm{ng} / \mathrm{mL}$ while the PSA trigger to reinitiate treatment was $20 \mathrm{ng} /$ $\mathrm{mL}$. The duration of each treatment cycle in the IAD arm was at least 6 months. The median follow-up was 65 months. 392 (71\%) of the patients died, $186(68 \%)$ in the IAD arm and $206(74 \%)$ in the continuous arm. Primary endpoints were progression free survival, PCa specific survival and overall survival. No statistically important differences were reported in any of the three specified endpoints between the two treatment arms. Median overall survival was 45.2 months in the IAD and 45.7 months in the CAD group (HR: 1.15; $p=0.17$ ), median PCa specific survival was 45.2 months in tha IAD and 44.3 months in CAD arm (HR: $1.17 ; p=0.29$ ) while median time to progression was 34.5 months in the IAD and 30.2 months in the continuous group (HR: $1.08 ; \mathrm{p}=0.43)$.

Calais da Silva et al., (20) in the Southern European Uroncological Group (SEUG) study enrolled 766 patients with locally advanced or metastatic cancer who received a 3-month induction treatment with GnRH analogue and cyproterone acetate. Patients with PSA nadir value below 4ng/ $\mathrm{mL}$ or a $80 \%$ reduction in the initial pre-treatment PSA were randomized in 2 groups (626 patients). In the IAD arm, in men with PSA nadir below $4 \mathrm{ng} / \mathrm{mL}$, PSA trigger for reinitiating treatment was $10 \mathrm{ng} / \mathrm{mL}$ for symptomatic patients and $20 \mathrm{ng} / \mathrm{mL}$ for asymptomatic patients. In men with $80 \%$ reduction of the pretreatment PSA, therapy reinitiated when PSA value rose to $20 \%$ of the nadir measurement. In the continuous arm complete androgen deprivation was deployed. There was no difference in overall survival [HR 0.99; CI 0.80 to 1.23 ] and disease progression [HR $0.81 ; \mathrm{p}=0.11$ ] between the two groups. In the IAD arm, cancer deaths were higher whereas in the CAD arm cardiovascular deaths increased. Furthermore, cost was by far reduced in the IAD arm. Time to castration-resistance was non-significantly different between the two groups. Authors concluded that intermittent therapy should be considered for use in routine practice and that an on-treatment phase of only 3 months seems to be efficient. However, the majority of these trials enrolled heterogeneous populations such as patients with different disease stages.

\section{Homogenous populations}

Langenhuijsen et al. in a TULP trial (21) enrolled 193 patients suffering from metastatic prostate cancer. 96 were treated with continuous $\mathrm{AD}$ and 97 with IAD. They announced that patients treated with IAD with a PSA nadir $<0.2 \mathrm{ng} / \mathrm{mL}$ had a statistically significant 2-year risk of progression compared to those treated with continuous $\mathrm{AD}$ (53\% in the IAD arm, 31\% in the continuous arm; $\mathrm{p}=0.03$ ).

The TAP22 trial (22) was a multicenter randomized study that enrolled 383 patients suffering from metastatic prostate cancer with PSA value $>$ 20ng/mL. Patients were randomized after a 6 month induction ADT if the PSA value decreased below $4 \mathrm{ng} / \mathrm{mL} .173$ patients were randomized and treated either with continuous or with intermittent $\mathrm{AD}$. PSA trigger point to stop ADT was below $4 \mathrm{ng} / \mathrm{mL}$ while therapy was reinitiated when PSA increased over $10 \mathrm{ng} / \mathrm{mL}$. Primary endpoint was overall survival, while secondary were progression-free survival, health related quality of life and safety criteria. No statistically significant differences arose between the treatment arms in terms of overall survival $(p=0.75)$ and progression-free survival $(p=0.74)$.

Two large randomized with homogeneous population and long-term follow-up trials have been performed. The National Cancer Institute of Canada NCT3653 (23) and the Southwest Oncology Group (SWOG) 9346 (24) trials were both designed as non-inferiority studies aiming to address the impact of ADT on overall and cause specific survival.

The NCT3653 study (23) was designed to investigate whether IAD treatment was inferior to CAD with respect to survival in patients with rising PSA after definite radiotherapy with no evidence of metastatic disease. The trial enrolled 1386 non metastatic patients with localized prostate cancer and PSA level higher than $3 \mathrm{ng} / \mathrm{mL}$ more than a year after radiotherapy. In the IAD arm, patients were 
treated with 8-month cycle of therapy of an LH-RH analogue combined with a non steroidal antiandrogen. At the end of the cycle treatment was withdrawn if the PSA level was below $4 \mathrm{ng} / \mathrm{mL}$. During the non-treatment period PSA was monitored every two months. The PSA trigger point for reinitiating therapy was determined at $10 \mathrm{ng} / \mathrm{mL}$. Median follow-up period was 6.9 years and primary endpoint was overall survival while secondary included QoL, duration of off-treatment and time to castration resistance. Overall median survival on the IAD group was 8.8 years with 268 deaths compared with 9.1 years and 256 deaths in the continuous group [HR: $1.02 ; 95 \%$ CI: 0.86 to 1.21]. Patients in the IAD arm were treated $27 \%$ of the time and $79 \%$ of them reached the trial entry threshold of testosterone recovery. In conclusion, NCT 3665 trial demonstrated an oncological equivalent efficiency of IAD compared to CAD in terms of overall and disease specific survival. In the intermittent arm prostate-cancer deaths were $9 \%$ increased but this difference was statistically non significant. As in SEUG trial, the increased prostate cancer deaths in the IAD group were scaled by increased non-prostate cancer deaths in the continuous arm. Although time to androgen independence was longer in the IAD group, the authors attributed this difference to a bias in the trial design. Only 35\% of the patients in the IAD arm returned to the pre-treatment levels of serum testosterone within two years after completing the first treatment period.

The SWOG trial (24) was designed with similar structure aiming to determine if survival with IAD is not inferior to CAD with respect to survival, in patients with hormone sensitive metastatic disease, using a one sided test with an upper bound hazard ratio of 1.2. The trial enrolled and randomized 1535 patients with metastatic disease, either lymph node, visceral or bone metastases, and a PSA greater than $5 \mathrm{ng} / \mathrm{mL}$. Patients were treated with a 7 month induction therapy with goserelin and bicalutamide. If the PSA was lower than 4ng/ $\mathrm{mL}$ patients were randomized in two groups. Treatment was reinitiated when PSA exceed $20 \mathrm{ng} / \mathrm{mL}$ and withdrawn again after 7 months if PSA was less than $4 \mathrm{ng} / \mathrm{mL}$. If PSA exceeded $4 \mathrm{ng} / \mathrm{mL}$ patients received CAD until progression. Primary endpoint was overall survival and secondary was QoL com- paring three treatment specific symptoms (impotence, libido, energy) and physical-emotional function. Overall median survival in the CAD group was 5.8 years while $29 \%$ of the patients survived for at least 10 years. On the other hand, overall median survival in the IAD group was 5.1 years while 23\% of the patients survived for at least 10 years. The authors concluded that although their results were statistically inconclusive, intermittent $A D$ may compromise survival in men with metastatic prostate cancer, based on their pre-specified definition of survival comparability [HR: 1.09; 95\% CI: 0.95 to 1.24$]$.They could not rule out a $20 \%$ greater risk of death with intermittent rather than continuous therapy. In an additional sub-analysis, IAD proved to be non inferior in patients with extensive disease (any or a combination of long bones, ribs, skull or viscera) [HR for death with IAD: 1.02 ; 95\% CI: 0.85 to 1.23 ] while in patients with minimal disease (metastasis confined to axial skeleton and pelvis or to lymph nodes) CAD proved to be statistically significantly superior [HR for death with IAD: 1.19; 95\% CI: 0.98 to 1.43] (Table-1).

Testosterone: Castration levels in ADT and recovery levels in IAD

During ADT, breakthroughs in serum testosterone levels seem to have negative clinical consequences. In the last few years, a reassessment of the serum testosterone levels for clinical castration is consented and the testosterone threshold of castration is shifted from $50 \mathrm{ng} / \mathrm{dL}$ to $20 \mathrm{ng} / \mathrm{dL}(27,28)$.

Nevertheless, prospective trials analyzing the impact of serum testosterone levels are not available yet. Morote et al., in a retrospective trial attempted to determine the optimum testosterone levels in patients treated with ADT, in terms of survival (29). He enrolled 73 patients with non metastatic disease treated with a 3-month GnRH analogue who had at least 3 measurements of serum testosterone in follow-up > 1 year. Authors defined testosterone threshold at $20 \mathrm{ng} / \mathrm{mL}$ and define androgen independent progression (AIP) as three consecutive rises from PSA nadir. They announced that testosterone breakthroughs are directly linked to PSA progression and that $32 \mathrm{ng} / \mathrm{dL}$ is the testosterone threshold for a clinical impact. Patients whom all three testosterone measurements were 


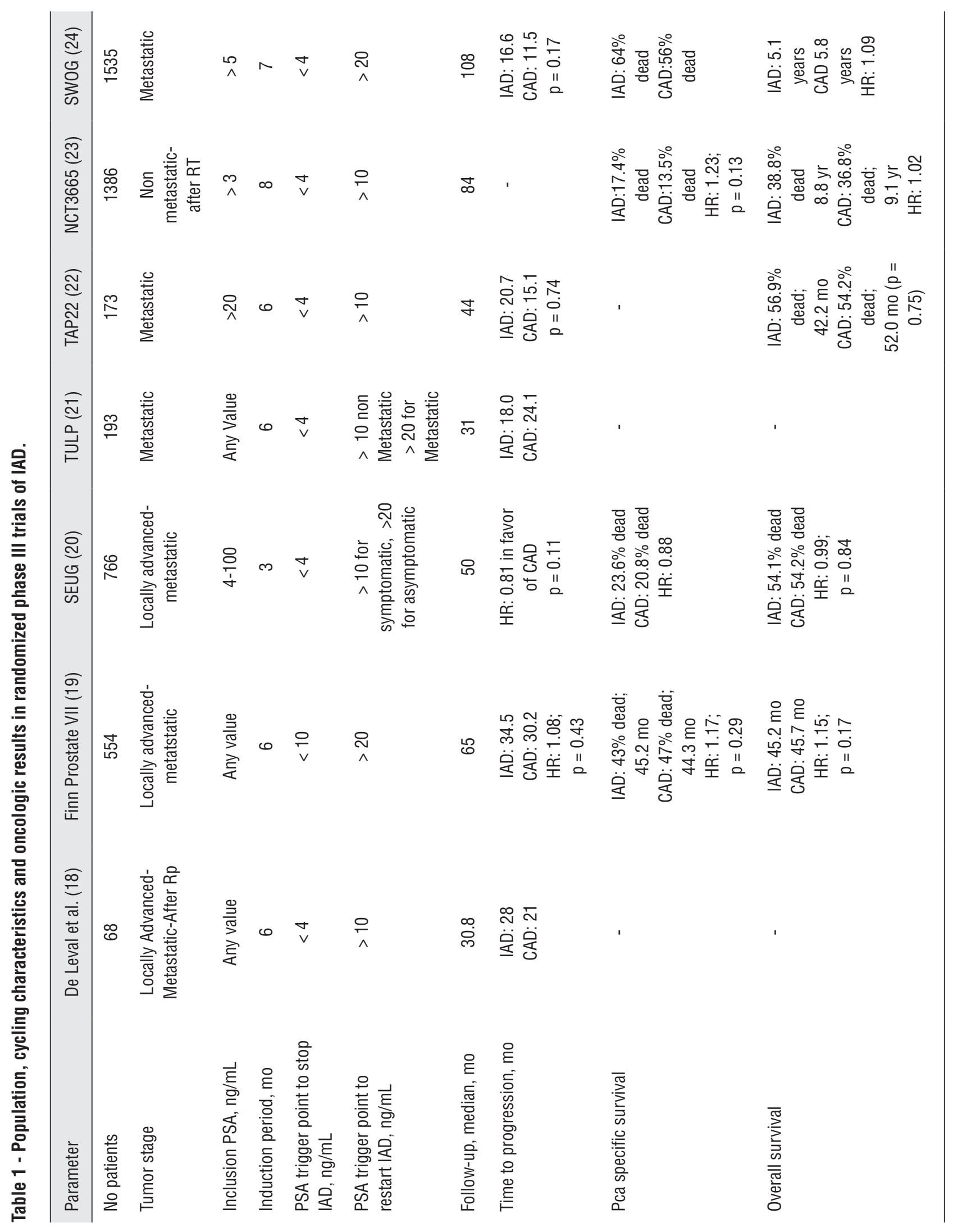


under $32 \mathrm{ng} / \mathrm{mL}$ had a median AIP-free survival of 137 months compared to 88 months for those with any breakthrough above $32 \mathrm{ng} / \mathrm{mL}$.

Hence, apart from AIP-free survival, Perachino et al. (28) correlated testosterone levels of ADP to the risk of death. Their retrospective study involved 129 patients with metastatic bone-only disease. Patients were treated with a three-month depot goserelin. PSA and testosterone levels were measured every three months. A Cox regression model was utilized to identify independent predictors of cancer free survival. Authors announced that Gleason score $(\mathrm{P}<0.01)$, 6-month PSA level $(\mathrm{P}<0.01)$ and 6-month serum testosterone level $(\mathrm{P}<0.05$; HR: 1.32) were independent predictors of cancer free survival, correlated directly with the risk of death. They found that the initial pre-treatment testosterone level did not predict survival while baseline PSA $(\mathrm{P}<0.01)$ and 6 month serum testosterone level $(\mathrm{P}=$ $0.0286)$ correlated directly with overall survival.

These recent data appear to be in total contrast with the rationale of IAD therapy. In IAD therapy recovery of testosterone in the off treatment periods is the primary cause of less adverse effects and improved QoL in patients. Testosterone rises in off treatment periods and yet according to the trials this rise has no adverse effect on overall survival. This still remains a great unsolved mystery and only hypothesis can be made regarding the answer. The level of testosterone recovery varies and appears to be affected by different factors such as baseline testosterone, duration of ADT treatment, patient age and ethnicity (30). Moreover testosterone recovery lags with successive cycles of therapy. Along with the testosterone recovery, duration of the off treatment period varies among the phase III trials ranging from $50 \%$ to $82 \%(15,20,23)$. Off treatment duration, along with testosterone recovery, is reduced with successful cycles of therapy, probably reflecting a gradual acquisition of androgen independence phenotype in the cancer cells.

\section{Adverse effects and quality of life}

Continuous ADT is associated with several early and long term adverse effects. Hot flushes and sexual dysfunction appears to be the most prevalent and common early side effects of ADT (31). Although the benefit in the QoL is not as profound as the expected, in some phase III trials QoL is ameliorated during the off treatment periods of $\operatorname{IAD}(15,16,21$ 23). In the TAP22 (22) study, patients treated with IAD experienced significantly fewer adverse effects (84.4\%) than patients treated with continuous AD $(93.6 \%)(p=0.042)$. In the NCT3653 trial (23), QoL was ameliorated in the intermittent groups in terms of erectile function, libido $(\mathrm{P}<0.001)$, hot flashes $(\mathrm{P}<0.001)$, fatigue $(\mathrm{P}=0.07)$, urinary symptoms $(\mathrm{P}$ $=0.006)$ and physical condition. In the SEUG trial (20), in the IAD arm there were fewer side effects such as hot flashes, gynecomastia and headaches reported and patients showed better sexual function and increased sexual activity $(\mathrm{P}<0.01)$. The FinnProstate VII phase III trial (32) announced a study that was specifically focused on the affect of $\mathrm{IAD}$ on the adverse effects and on the QoL. Decreased incident of hot flushes $(p=0.44)$ was reported in the IAD arm but the result was statistically non-significant. An unexpected statistically significant result arose with respect to erectile dysfunction and depression, which were more common in the IAD group of treatment $(p<0.05)$. In the SWOG trial (24), IAD treatment was associated with better erectile function $(\mathrm{P}<0.001)$ and mental health $(\mathrm{P}$ $=0.003$ ) at month 3 but not thereafter. In conclusion, according to the reviewed data, IAD therapy is pursued by a decreased incidence of early adverse effects such as hot flushes and sexual dysfunction.

$\mathrm{ADP}$ has also been correlated with long-term adverse effects such as metabolic syndrome and bone mineral density decline. GnRH analogues increase abdominal weight and decrease muscle size (33) and insulin sensitivity (34). These metabolic changes seem to have an impact on cardiovascular health. Recently FDA mentioned an increased risk of diabetes, heart attack, sudden death and stroke with GnRH analogues (35). In the SEUG (20) trial an increased risk of dying from cardiovascular disease in the continuous arm was reported (cardiovascular deaths: 52 [16.7\%] in the continuous arm, $41[13.1 \%]$ in the IAD group). Hence, in the FinnProstate VII trial (32), no significant differences arose between the treatment arms in terms of cardiovascular adverse effects $(\mathrm{P}=0.59)$ and cardiovascular-related mortality $(\mathrm{P}=0.38)$. Thus, due to limited existing data, this issue remains ambiguous and blinded randomized trials are required. Bone 
mineral density declines with ADT increasing the risk of fractures and osteoporosis. In continuous ADT biophosphonates should be considered in patients with fracture or BMD $\mathrm{T}$ scores of -2.5 or less (36). Spry et al. (37) reported that in 72 patients treated with IAD, BMD decrease was lagged during the off treatment intervals. Moreover, testosterone recovery levels were strongly correlated with BMD changes.

Furthermore, as far as QoL is concerned, only the SEUG (20) and the FinnProstate VII (32) trial reported some significant differences, mainly in terms of sexual function and activity limitation. A possible explanation for this might be that the off treatment periods are too short to alter significantly the QoL. Another cause might be that the questionnaires are not adapted to indicate so limited differences. It is also essential to mention that in all trials, except from the FinnProstate VII, QoL was assessed at fixed points regardless of the treatment phase, leading to the evaluation of patients both in on and off treatment phase in the IAD arm. This approach of evaluation may compromise the results in the in QoL differences between the two arms (Table-2).

\section{IAD monitoring, trigger points and prognostic factors}

The optimal thresholds of withdrawing and reinitiating $\mathrm{AD}$ are empirical. In almost all Phase III studies PSA levels rather than testosterone levels have been used as trigger points of resuming or withdrawing the AD. Most of the patients required 6 to 9 months to achieve PSA nadir. A prolonged induction cycle (more than a year) is considered as inappropriate for IAD, as testosterone recovery is unlikely. Most of Phase III trials required a PSA nadir value less than $4 \mathrm{ng} / \mathrm{mL}$ after induction cycle before withdrawing AD. PSA threshold of resuming therapy varies among trials and was empirically set between 10 and $20 \mathrm{ng} / \mathrm{mL}$, depending on the disease stage. In patients treated with IAD, PSA and testosterone levels should be monitored at least every 3 months.

In patients treated with ADT, PSA nadir is a strong predictor of early progression $(15,20,21)$. In IAD, PSA nadir is also predictive (21). According to Sciarra et al., in men treated with IAD a failure to achieve PSA nadir lower than $0.4 \mathrm{ng} / \mathrm{mL}$, after the first cycle, is associated with an increased risk of clinical progression and development of castration resistant disease (38). Thus, the duration of the off treatment period has also been proven to be predictive for the time to progression. According to two recent studies shorter off treatment period correlates to a 3.8 risk for death and a 2.9 risk for disease progression $(38,39)$.

\section{International Guidelines}

EAU was the first international urological association that included IAD as an alternative therapy for advanced prostate cancer in its 2012 guidelines stating that IAD should no longer be considered as investigational (25). EAU stated in the guidelines that the possible benefit of CAD in disease progression is balanced by the increased toxicity and adverse effects, leading to absence of difference in overall survival. According to EAU, although the overall amelioration in the QoL is less than the expected, IAD is better tolerated having benefits for the sexual functioning.

In contrast to EAU, the American Urological Association (AUA) has not included IAD in its guidelines yet (40), while American Society of Clinical Oncology (ASCO) states that the existing data is still insufficient for the use of IAD outside clinical trials (41). The National Comprehensive Cancer Network (NCCN) guidelines state that IAD may reduce adverse effects without difference in overall survival in comparison to CAD. Nevertheless, IAD's long term efficacy has not been proven yet (42) (Table-3).

\section{General recommendations and future perspectives}

Based on the data reviewed, men with biochemical recurrence after definite therapy are the most appropriate candidates for IAD, since the majority of them have no bone metastasis. Based on the SWOG trial, patients suffering from hormone sensitive metastatic disease should be treated with continuous $\mathrm{AD}$ (24). As mentioned, PSA nadir value is a strong predictor of progression and can be used for the evaluation of the response to the treatment along with the clinical response. Thus, patients with undetected PSA value and after induction treatment with $\mathrm{AD}$ should be considered as suitable for IAD. A 


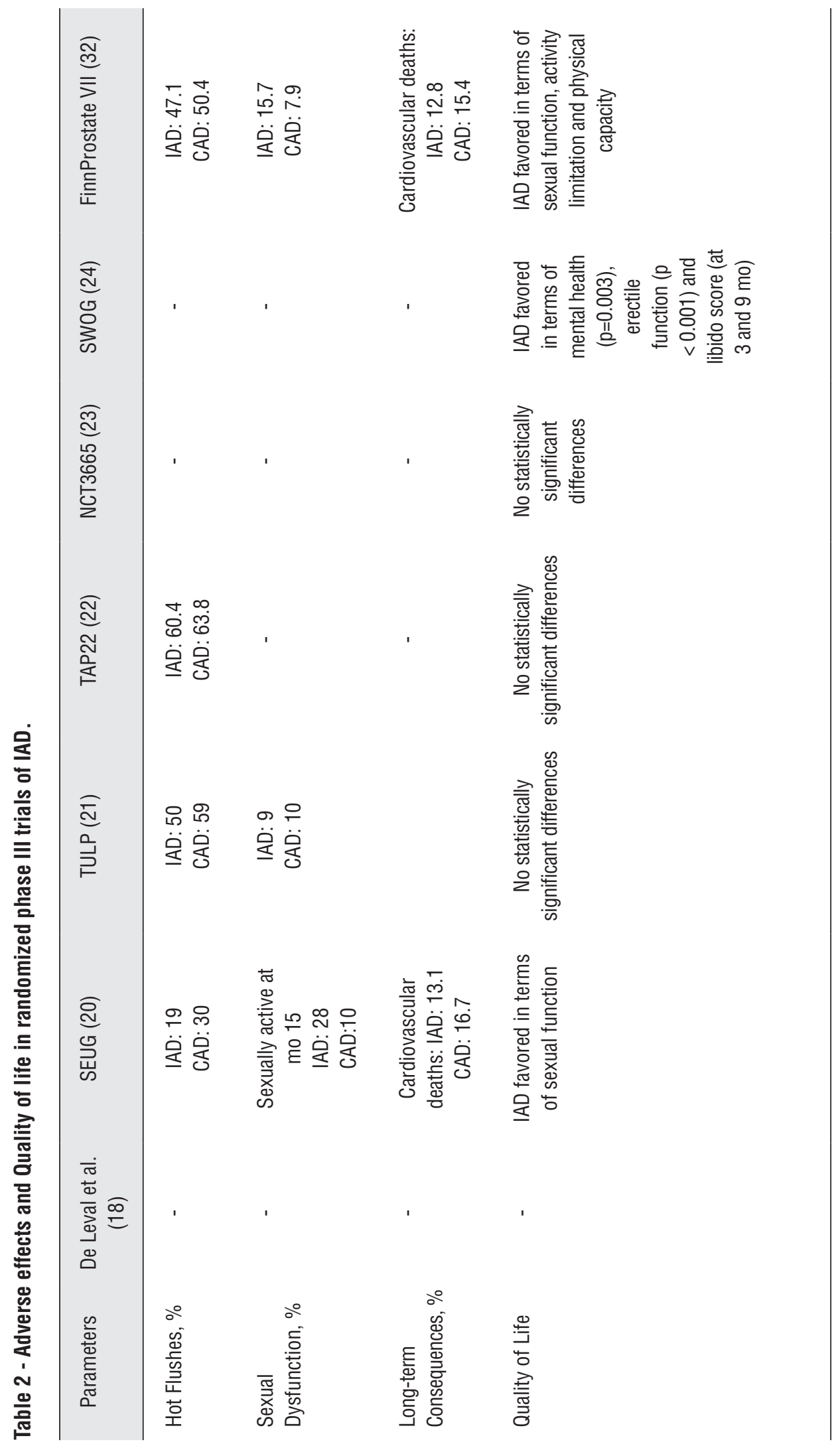


Table 3 - International guidelines for IAD.

\begin{tabular}{|c|c|c|c|c|}
\hline Guideline & EAU 2013 (5) & AUA 2007 (35) & ASCO 2007 (36) & NCCN 2012 (37) \\
\hline Recommendation & $\begin{array}{l}\text { IAD is currently widely } \\
\text { offered to patients } \\
\text { with PCa in various } \\
\text { clinical settings, and } \\
\text { its status should no } \\
\text { longer be regarded as } \\
\text { investigational }\end{array}$ & IAD is not included yet & $\begin{array}{l}\text { Existing data is still } \\
\text { insufficient for the use } \\
\text { of IAD outside clinical } \\
\text { trials }\end{array}$ & $\begin{array}{l}\text { IAD may reduce } \\
\text { adverse effects without } \\
\text { difference in survival } \\
\text { in comparison to } \\
\text { continuous ADT, but } \\
\text { long term efficacy has } \\
\text { not proven yet }\end{array}$ \\
\hline
\end{tabular}

failure in achieving a low PSA nadir should exclude patients from IAD. Apart from failure in low PSA nadir, men with bulky tumors, extended nodal and bone metastasis, severe pain, PSA above 100ng/mL and rapid PSA progression should not be considered as appropriate candidates for IAD $(43,44)$.

According to the reviewed data, along with EAU guidelines, an induction cycle of 8 to 9 months is recommended. Patients with biochemical response should be treated with IAD. The threshold of accepted biochemical support is empirically defined as PSA nadir value below $4 \mathrm{ng} / \mathrm{mL}$. Close scrutiny is essential in the off treatment periods, since the treatment is withdrawn. Every 3 to 6 months patients should be screened with clinical examination, PSA levels and testosterone levels. PSA trigger points for reinitiating treatment are $10 \mathrm{ng} / \mathrm{mL}$ for asymptomatic patients and $15 \mathrm{ng} / \mathrm{mL}$ for symptomatic ones. The on treatment period should be at least 6 months and subsequent cycles continue until clinical evidence of development of castration resistant disease.

Furthermore, well organized large scale randomized Phase III trials are required in order to illuminate several crucial aspects in IAD treatment that remain obscure. Defining the clear response to the treatment, clarifying the PSA kinetics and setting the optimum PSA trigger points are essential in order to achieve better treatment results with IAD. Hence, elucidating more specific patients' selection criteria is substantial in order to maximize the benefits of IAD as treatment. Illustrating the effect and the influence that pre-treatment factors such as Gleason score, disease extension and pre-treatment PSA might have to the treatment results is also extremely important. Several agents have been studied aiming to prolong the duration of the off treatment period in IAD, including finasteride (45), pazopanib (46) COX-2 inhibitors (47) and thalidomide (48). The results of these primary studies are encouraging especially for the use of thalidomide and finasteride but larger scale, randomized and double-blinded trials are required to achieve definite answers.

\section{CONCLUSIONS}

IAD appears as a suitable therapy for many patients suffering from advanced and recurrent prostate cancer. Based on the results of Phase III trials, IAD is oncological non inferior to $\mathrm{CAD}$ in terms of overall and disease free survival in patients with biochemical recurrence. Thus, in patients with metastatic disease the proper treatment remains ambiguous and consensus is not reached yet. Hence, continuous AD seems to be a more secure treatment up until today. On the other hand, considering the additional benefits of IAD in the QoL and the cost reduction, IAD appears to be a very appealing alternative treatment for advanced and recurrent prostate cancer. Nevertheless, more multicenter well-designed randomized trials are necessary in the future, in order to clarify several vague aspects in the treatment of advanced prostate cancer.

\section{ABBREVIATIONS}

ADT $=$ Androgen Deprivation Therapy

$\mathrm{IAD}=$ Intermittent androgen deprivation

DES $=$ Diethylstilbestrol

GnRH = Gonadotropin-releasing hormone

EAU $=$ European Association of Urology 
$\mathrm{PCa}=$ Prostate cancer

LH = Luteinizing Hormone

$\mathrm{T}=$ Testosterone

DET $=$ Dihydrotestosterone

PSA $=$ Prostate specific antigen

QoL $=$ Quality of Life

$\mathrm{CAD}=$ Continuous Androgen deprivation

SEUG = Southern European Uroncological Group

$\mathrm{HR}=$ Hazard Ratio

$\mathrm{CI}=$ Confidence Interval

SWOG = Southwest Oncology Group

AUA = American Urological Association

ASCO = American Society of Clincal Oncology

NCCN $=$ National Comprehensive Cancer Network

\section{REFERENCES}

1. Center MM, Jemal A, Lortet-Tieulent J, Ward E, Ferlay J, Brawley 0 , et al.: International variation in prostate cancer incidence and mortality rates. Eur Urol. 2012; 61: 1079-92.

2. Baade PD, Youlden DR, Krnjacki LJ: International epidemiology of prostate cancer: geographical distribution and secular trends. Mol Nutr Food Res. 2009; 53: 171-84.

3. EAU 2013 online guidelines: Prostate cancer: page 82. Available at http://www.uroweb.org/gls/pdf/09_Prostate_Cancer_LR.pdf

4. Byar DP, Corle DK: Hormone therapy for prostate cancer: results of the Veterans Administration Cooperative Urological Research Groupstudies. NCI Monogr. 1988; 7: 165-70.

5. de Voogt HJ, Smith PH, Pavone-Macaluso M, de Pauw M, Suciu S: Cardiovascular side effects of diethylstilbestrol, cyproterone acetate, medroxyprogesterone acetate and estramustine phosphate used for the treatment of advanced prostatic cancer: results from European Organization for Research onTreatment of Cancer trials 30761 and 30762. J Urol. 1986; 135: 303-7.

6. Higano CS: Side effects of androgen deprivation therapy: monitoring and minimizing toxicity. Urology. 2003; 61: 32-8.

7. Klotz LH, Herr HW, Morse MJ, Whitmore WF Jr.: Intermittent endocrine therapy for advanced prostate cancer. Cancer. 1986; 58: 2546-50. Erratum in: Cancer 1987; 59: 43.

8. Bruchovsky N, Rennie PS, Coldman AJ, Goldenberg SL, To M, Lawson D: Effects of androgen withdrawal on the stem cell composition of the Shionogi carcinoma. Cancer Res. 1990; 50: 2275-82.

9. Rennie PS, Bruchovsky N, Akakura K, Goldenberg SL, Otal $\mathrm{N}$, Akakura $\mathrm{S}$, et al.: Effect of tumour progression on the androgenic regulation of the androgen receptor, TRPM-2 and YPT1 genes in the Shionogi carcinoma. J Steroid Biochem Mol Biol. 1994; 50: 31-40.
10. Akakura K, Bruchovsky N, Goldenberg SL, Rennie PS, Buckley AR, Sullivan LD: Effects of intermittent androgen suppression on androgen-dependent tumors. Apoptosis and serum prostate-specific antigen. Cancer. 1993; 71: 2782-90.

11. Bruchovsky N, Goldenberg SL, Akakura K, Rennie PS: Luteinizing hormone-releasing hormone agonists in prostate cancer. Elimination of flare reaction by pretreatment withcyproterone acetate and low-dose diethylstilbestrol. Cancer. 1993; 72: 1685-91.

12. Eggener SE, Stern JA, Jain PM, Oram S, Ai J, Cai X, et al.: Enhancement of intermittent androgen ablation by "offcycle" maintenance with finasteride in LNCaP prostate cancerxenograft model. Prostate. 2006; 66: 495-502.

13. Goldenberg SL, Bruchovsky N, Gleave ME, Sullivan LD, Akakura K: Intermittent androgen suppression in the treatment of prostate cancer: a preliminary report. Urology. 1995; 45: 839-44; discussion 844-5.

14. Shaw GL, Wilson P, Cuzick J, Prowse DM, Goldenberg SL, Spry NA, et al.: International study into the use of intermittent hormone therapy in the treatment of carcinoma of the prostate: a meta-analysisof 1446 patients. BJU Int. 2007; 99: 1056-65.

15. Miller K, Steiner U, Lingnau A, Keilholz U, Witzsch U, Haider $A$, et al.: Randomised prospective study of intermittent versus continuous androgen suppression in advanced prostate cancer. J Clin Oncol 2007; 25: 18S [abstract 5105].

16. Tunn U, Eckhart 0 , Kienle E, Hillger $\mathrm{H}$ : Intermittent androgen deprivation in patients with psa-relapse after radical prostatectomy - first results of a randomised prospective phase-iii clinical trial (AU0 study AP06/95). Eur Urol Suppl 2003; 2: 24.

17. Verhagen PC, Wissenburg LD, Wildhagen MF: Quality of life effects of intermittent and continuous hormonal therapy by cyproterone acetate (сра) for metastatic prostate cancer. Eur Urol Suppl. 2008; 7: 206.

18. de Leval J, Boca P, Yousef E, Nicolas H, Jeukenne M, Seidel $\mathrm{L}$, et al.: Intermittent versus continuous total androgen blockade in the treatment of patients with advanced hormone-naive prostate cancer: results of a prospective randomized multicenter trial. Clin Prostate Cancer. 2002; 1: 163-71.

19. Salonen AJ, Taari K, Ala-Opas M, Viitanen J, Lundstedt S, Tammela TL; et al.: The FinnProstate Study VII: intermittent versus continuous androgen deprivation in patients with advanced prostate cancer. J Urol. 2012; 187: 2074-81.

20. Calais da Silva FE, Bono AV, Whelan P, Brausi M, Marques Queimadelos A, Martin JA, Kirkali Z, et al.: Intermittent androgen deprivation for locally advanced and metastatic prostate cancer: results from a randomised phase 3 study of the South European Uroncological Group. Eur Urol. 2009; 55: $1269-77$. 
21. Langenhuijsen JF, Badhauser D, Schaaf B, Kiemeney LA, Witjes JA, Mulders PF: Continuous vs. intermittent androgen deprivation therapy for metastatic prostate cancer. Urol Oncol. 2013; 31: 549-56.

22. Mottet N, Van Damme J, Loulidi S, Russel C, Leitenberger A, Wolff JM; et al.: Intermittent hormonal therapy in the treatment of metastatic prostate cancer: a randomized trial. BJU Int. 2012; 110: 1262-9.

23. Crook JM, O'Callaghan CJ, Duncan G, Dearnaley DP, Higano CS, Horwitz EM, et al.: Intermittent androgen suppression for rising PSA level after radiotherapy. N Engl J Med. 2012; 367: 895-903. Erratum in: N Engl J Med. 2012; 367: 2262.

24. Hussain M, Tangen CM, Berry DL, Higano CS, Crawford ED, Liu G, et al.: Intermittent versus continuous androgen deprivation in prostate cancer. N Engl J Med. 2013; 368: 1314-25.

25. EAU 2013 online guidelines: Prostate cancer: page 90. Available at in http://www.uroweb.org/gls/pdf/09_Prostate_ Cancer_LR.pdf

26. Abrahamsson PA: Potential benefits of intermittent androgen suppression therapy in the treatment of prostate cancer: a systematic review of the literature. Eur Urol. 2010; 57: 49-59.

27. Oefelein MG, Feng A, Scolieri MJ, Ricchiutti D, Resnick MI: Reassessment of the definition of castrate levels of testosterone: implications for clinical decision making. Urology. 2000; 56: 1021-4.

28. Perachino M, Cavalli V, Bravi F: Testosterone levels in patients with metastatic prostate cancer treated with luteinizing hormone-releasing hormone therapy:prognostic significance? BJU Int. 2010; 105: 648-51.

29. Morote J, Orsola A, Planas J, Trilla E, Raventós CX, Cecchini $L$, et al.: Redefining clinically significant castration levels in patients with prostate cancer receiving continuous androgendeprivation therapy J Urol. 2007; 178: 1290-5.

30. Gulley JL, Figg WD, Steinberg SM, Carter J, Sartor O, Higano $\mathrm{CS}$, et al.: A prospective analysis of the time to normalization of serum androgens following 6 months of androgen deprivation therapyin patients on a randomized phase III clinical trial using limited hormonal therapy. J Urol. 2005; 173: 1567-71. Erratum in: J Urol. 2005; 174: 796. Sartor, Oliver [added]; Higano, Celestia S [added]; Petrylak, Daniel $P$ [added] Chatta, Gerkamal [added].

31. Gruca D, Bacher P, Tunn U: Safety and tolerability of intermittent androgen deprivation therapy: a literature review. Int J Urol. 2012; 19: 614-25.

32. Salonen AJ, Taari K, Ala-Opas M, Viitanen J, Lundstedt S, Tammela TL; et al.: Advanced prostate cancer treated with intermittent or continuous androgen deprivation in the randomised FinnProstateStudy VII: quality of life and adverse effects. Eur Urol. 2013; 63: 111-20.
33. Smith MR, Finkelstein JS, McGovern FJ, Zietman AL, Fallon MA, Schoenfeld DA, et al.: Changes in body composition during androgen deprivation therapy for prostate cancer. J Clin Endocrinol Metab. 2002; 87: 599-603.

34. Smith MR, Lee $H$, Nathan DM: Insulin sensitivity during combined androgen blockade for prostate cancer. J Clin Endocrinol Metab. 2006; 91: 1305-8.

35. US Food and Drug Administration (FDA). FDA Drug Safety Communication 10-20-2010. Available at http://www. fda.gov/Drugs/DrugSafety/ucm229986.htm. Accessed January 17, 2012.

36. Sharifi N, Gulley JL, Dahut WL: An update on androgen deprivation therapy for prostate cancer. Endocr Relat Cancer. 2010; 17: R305-15.

37. Spry NA, Galvão DA, Davies R, La Bianca S, Joseph D, Davidson $A$, et al.: Long-term effects of intermittent androgen suppression on testosterone recovery and bone mineral density: results of a 33-month observational study. BJU Int. 2009; 104: 806-12.

38. Sciarra A, Cattarino S, Gentilucci A, Alfarone A, Innocenzi $M$, Gentile V, et al.: Predictors for response to intermittent androgen deprivation (IAD) in prostate cancer cases with biochemical progression after surgery. Urol Oncol. 2013; 31: 607-14.

39. Yu EY, Gulati R, Telesca D, Jiang P, Tam S, Russell KJ, et al.: Duration of first off-treatment interval is prognostic for time to castration resistance and death in men with biochemical relapse of prostate cancer treated on a prospective trial of intermittent androgen deprivation. $J$ Clin Oncol. 2010; 28: 2668-73.

40. Prostate cancer. Guideline for the management of clinically localized prostate cancer: 2007 update. American Urological Association Web site. Available at http://www.auanet.org/content/guideline-and-qualitycare/clinical-guidelines/main-reports/proscan07/ content.pdf

41. Loblaw DA, Virgo KS, Nam R, Somerfield MR, Ben-Josef $\mathrm{E}$, Mendelson DS, et al.: Initial hormonal management of androgen-sensitive metastatic, recurrent, or progressive prostate cancer: 2006 update of an American Society of Clinical Oncology practice guideline. J Clin Oncol. 2007; 25: 1596-605.

42. Mohler JL, Armstrong AJ, Bahnson RR, Boston B, Busby JE, D’Amico AV, et al.: Prostate cancer, Version 3.2012: featured updates to the NCCN guidelines. J Natl Compr Canc Netw. 2012; 10: 1081-7.

43. Salonen AJ, Viitanen J, Lundstedt S, Ala-Opas M, Taari K, Tammela TL; et al.: Finnish multicenter study comparing intermittent to continuous androgen deprivation for advanced prostate cancer:interim analysis of prognostic markers affecting initial response to androgen deprivation. J Urol. 2008; 180: 915-9; discussion 919-20. 
44. Prapotnich D, Fizazi K, Escudier B, Mombet A, Cathala N, Vallancien G: A 10-year clinical experience with intermittent hormonal therapy for prostate cancer. Eur Urol. 2003; 43: 233-39; discussion 239-40.

45. Scholz MC, Jennrich RI, Strum SB, Johnson HJ, Guess BW, Lam RY: Intermittent use of testosterone inactivating pharmaceuticals using finasteride prolongs the time off period. J Urol. 2006; 175: 1673-8.

46. Ward JE, Karrison T, Chatta G, Hussain M, Shevrin D, Szmulewitz RZ, et al.: A randomized, phase II study of pazopanib in castrate-sensitive prostate cancer: a University of Chicago Phase IIConsortium/Department of Defense Prostate Cancer Clinical Trials Consortium study. Prostate Cancer Prostatic Dis. 2012; 15: 87-92.
47. Di Silverio F, Sciarra A, Gentile V: Etoricoxib and intermittent androgen deprivation therapy in patients with biochemical progression after radical prostatectomy. Urology. 2008; 71: 947-51.

48. Figg WD, Hussain MH, Gulley JL, Arlen PM, Aragon-Ching JB, Petrylak DP, et al.: A double-blind randomized crossover study of oral thalidomide versus placebo for androgen dependent prostate cancer treated with intermittent androgen ablation. J Urol. 2009; 181: 1104-13; discussion 1113.

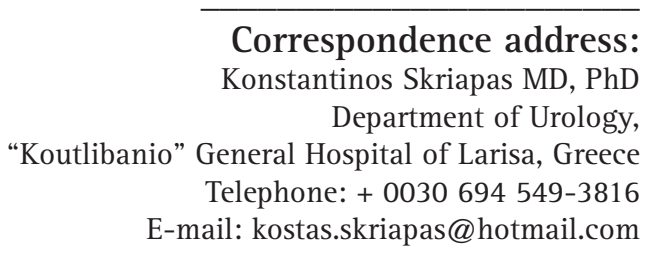

One concern in the trials in which serum testosterone was measured along with PSA in the follow-up of patients receiving intermittent androgen deprivation therapy is that testosterone levels take a long time to level up after the suspension of the androgen suppression, many times more than one year, and that would signify that in reality patients in "intermittent" hormone suppression actually are being suppressed for many months after stopping antiandrogenic therapy.

We believe that intermittent suppression is really no longer experimental, but testosterone levels, as well as PSA, bone density status, and clinical parameters must be measured as closely in the follow-up of these men as in the follow-up of those men receiving continuous androgen deprivation.

\section{REFERENCES}

1. Mottet N, Van Damme J, Loulidi S, Russel C, Leitenberger A, Wolff JM, et al.: Intermittent hormonal therapy in the treatment of metastatic prostate cancer: a randomized trial. BJU Int. 2012; 110: 1262-9.

2. Niraula S, Le LW, Tannock IF: Treatment of prostate cancer with intermittent versus continuous androgen deprivation: a systematic review of randomized trials. J Clin Oncol. 2013; 31: 2029-36.

\author{
Gustavo Franco Carvalhal, $M D, P h D$ \\ Postgraduate Course in Medicine and \\ Health Sciences, PUCRS \\ Section Editor, Int Braz J Urol \\ E-mail:gcarvalhal@terra.com.br
}

